\title{
Study of Fluoride Affinity by Zirconium Impregnated Walnut Shell Carbon in Aqueous Phase: Kinetic and Isotherm Evaluation
}

\author{
M. Rajan, ${ }^{1}$ and G. Alagumuthu' ${ }^{2}$ \\ ${ }^{1}$ Department of Chemistry, Periyar University, Tamilnadu, Salem 636 011, India \\ ${ }^{2} P G \&$ Research Centre of Chemistry, Sri Paramakalyani College, Tamilnadu, Alwarkurichi 627 412, India \\ Correspondence should be addressed to G. Alagumuthu; alagupathi@yahoo.co.in
}

Received 26 June 2012; Accepted 16 October 2012

Academic Editor: Gunnar Nyman

Copyright (c) 2013 M. Rajan and G. Alagumuthu. This is an open access article distributed under the Creative Commons Attribution License, which permits unrestricted use, distribution, and reproduction in any medium, provided the original work is properly cited.

\begin{abstract}
This paper examines the kinetics of fluoride removal from water by the adsorbent zirconium-impregnated walnut-shell carbon (ZIWSC), exploring the mechanisms involved. The dependence of the adsorption of fluoride on the $\mathrm{pH}$ of the solution has been studied to achieve the optimum $\mathrm{pH}$ value and a better understanding of the adsorption mechanism. The presence of bicarbonate ions in aqueous solution was found to affect the fluoride removal indicating that these anions compete with the sorption of fluoride on adsorbents. The kinetic profile has been modeled using pseudo-first-order model, pseudo-second-order model, and intraparticle diffusion model. The kinetic sorption profiles offered excellent fit with pseudo-second-order model. Adsorption isotherms have been modeled by Langmuir, Freundlich, and Temkin equations, and their constants were determined. The equilibrium adsorption data were fitted reasonably well for Freundlich isotherm model. XRD and SEM patterns of the ZIWSC were recorded to get better insight into the mechanism of adsorption process.
\end{abstract}

\section{Introduction}

Fluoride ion exists in natural waters and it is an essential micronutrient in human in preventing dental carries and in facilitating the mineralization of hard tissues. It takes at a recommended range of concentration $(1.0-1.5 \mathrm{mg} / \mathrm{L})$. Higher level of fluoride in ground water is a huge problem in all the countries including the USA, the Asian and the African countries [1]. It has become a global issue. In India, although water resources are high, there is an acute scarcity of safe drinking water due to acceptable water quality. According to the World Health Organization (WHO), the maximum acceptable concentration of fluoride in drinking water lies below $1.5 \mathrm{mg} / \mathrm{L}$ [2]. The incidence of high fluoride content in ground water $(>1.5 \mathrm{mg} / \mathrm{L})$ is common in both shallow and deeper water bearing $[3,4]$. Fluoride contamination in ground water arises both from natural causes and anthropogenic activities. Fluoride is a persistent and nondegradable poison that accumulates in soil, plants, wild life, and humans. The presence of fluoride ion in portable water has adverse effect on human health. Fluoride is affected by positive charged calcium in teeth and bones due to its strong electronegativity, which results in dental, skeletal and nonskeletal form of fluorosis in children as well as adults $[5,6]$. The dental and skeletal fluorosis is irreversible and no treatment exists. The only remedy is prevention by keeping fluoride intake within the safe limits.

The excess fluoride $(>1.5 \mathrm{mg} / \mathrm{L})$ in drinking water can be removed by various defluoridation techniques. Defluoridation technologies can be divided into following important categories, namely, chemical precipitation [7, 8], membrane processes [9], adsorption and ion exchange [10] and Nalgonda technique [11]. The adsorption process is the most commonly used technique for the fluoride removal from drinking water. The adsorption process is a widely acceptable pollution removal technique because of its ease of operation and cost-effectiveness. Large numbers of adsorbents have been studied for the removal of fluoride from water based on alumina [12], other minerals and metal oxides [1315], clays [15-17], carbons [18], zeolites [19], agricultural 
wastes [20,21], and so forth. Though the removal of fluoride using zirconium-impregnated cashew nut shell carbon [21], zirconium-impregnated ground nut shell carbon [22] has been reported earlier, the author felt that the use of ZIWSC could definitely give a new dimension in the field of defluoridation; hence defluoridation experiments were carried out using the ZIWSC.

In this study, waste walnut shell was utilized as the raw material for the production of activation carbon, which was impregnated with zirconium oxychloride by chemical methods, and its adsorption capacity for fluoride ions was evaluated. Johns et al. [23] utilized granular activated carbon (GACs) made from walnut hull to successfully remove higher levels of benzene, toluene, methanol, acetonotrile, acetone, and 1,4-dioxane from an aqueous mixture rather than commercial GACs. The effects of contact time, dosage, solution $\mathrm{pH}$, fluoride concentration, and reaction temperature on fluoride were studied in details.

\section{Materials and Methods}

2.1. Preparation of Activated Carbon. The walnut shell was taken from local natural resources. The materials were cleaned and dried to constant weight at room temperature and then activated as per the procedure [24]. About $100 \mathrm{~g}$ of the crushed walnut shell was kept for 3 hours in a lowtemperature muffle furnace at $573-673 \mathrm{~K}$. The carbonized material was taken out of the muffle furnace, cooled, powdered, and kept in a beaker and $200 \mathrm{~mL}$ of concentrated sulphuric acid was gradually added to it and the contents were stirred continuously to ensure thorough mixing. The activated carbon was then cooled and left overnight and washed free of acid and dried at $383 \mathrm{~K}$ for 2 hours, and then sieved using various mesh sizes. Subsequently the activated carbon was further immersed in $2 \mathrm{~N} \mathrm{NaOH}$ solution and washed free of alkali, providing the desired adsorbent for impregnation.

Zirconium ion impregnation was carried out by adding $5 \% \mathrm{ZrOCl}_{2}$ solution with activated carbon (solution/solid ratio $=2: 1$ ) and the mixture was kept for three days at room temperature $(298 \mathrm{~K})$. The impregnated carbon was then filtered, rinsed to confirm the effluent free from zirconium, dried in an oven at $380 \mathrm{~K}$ and subsequently used for defluoridation studies. The defluoridation capacity of ZIWSC was investigated by pursuing the batch equilibrium and kinetic experiments. The reagents used in this present study are of analytical grade. A fluoride ion stock solution $(100 \mathrm{mg} / \mathrm{L})$ was prepared and other fluoride test solutions were prepared by subsequent dilution of the stock solution. All the experiments were carried out at room temperature. Fluoride ion concentration was measured with a specific ion selective electrode by use of total ionic strength adjustment buffer (TISAB) solution to maintain $\mathrm{pH} 5$ to 5.5 and to eliminate the interference effect of complexing ions [25]. Fluoride ion concentration and $\mathrm{pH}$ of the samples were measured by Orion ion selective electrode equipment. All the other water quality parameters were analysed by using standard methods [26].
2.2. Sorption Experiments. The sorption isotherm and kinetics experiments were performed by batch adsorption experiments and were carried out by mixing $1.5 \mathrm{gm}$ of sorbent with $100 \mathrm{~mL}$ of sodium fluoride containing $3 \mathrm{mg} / \mathrm{L}$ as initial fluoride concentration. The mixture was agitated in a thermostatic shaker at a speed of $200 \mathrm{rpm}$ at room temperature. The defluoridation studies were conducted for the optimization of various experimental conditions like contact time, $\mathrm{pH}$, initial fluoride concentration, and influence of coions with fixed dosage. Kinetic studies of sorbent were carried out in a temperature-controlled mechanical shaker. The effect of different initial fluoride concentrations, namely, 2, 4, 6, 8 and $10 \mathrm{mg} / \mathrm{L}$ at four different temperatures, namely, 303, 313, 323 and $333 \mathrm{~K}$ on sorption rate were studied by keeping the mass of sorbent as $1.5 \mathrm{gm}$ and volume of solution as $100 \mathrm{~mL}$ in neutral $\mathrm{pH}$. The $\mathrm{pH}$ at zero point charge $\left(\mathrm{pH}_{\mathrm{zpc}}\right)$ of sorbent was measured using the $\mathrm{pH}$ drift method [27]. The $\mathrm{pH}$ of the solution was adjusted by using $0.01 \mathrm{~mol} / \mathrm{L}$ sodium hydroxide or hydrochloric acid. Nitrogen was bubbled through the solution at $30^{\circ} \mathrm{C}$ to remove the dissolved carbon dioxide. $50 \mathrm{mg}$ of the adsorbent was added to $50 \mathrm{~mL}$ of the solution. After stabilization, the final $\mathrm{pH}$ was recorded. The graph of final $\mathrm{pH}$ versus initial $\mathrm{pH}$ was used to determine the zero point charge of the activated carbon.

2.3. Characterisation of Sorbents. The X-ray diffraction (XRD) pattern of the impregnated carbon was obtained using a Bruker AXS D8 Advance, Inst ID: OCPL/ARD/26-002 Xray diffractometer. Examination of adsorption with Scanning Electron Microscope (SEM) with HITACHI-S-3400N model fitted with an energy dispersive X-ray analyzer (EDAX) allows a qualitative detection and localization of elements in the adsorption. The SEM enables a direct observation of the surface microstructures of the fresh and fluoride-adsorbed adsorbents.

\section{Results and Discussion}

3.1. Effect of Contact Time and Concentration. In order to determine the equilibration time for maximum adsorption of fluoride and to know the kinetics of adsorption process, the adsorption of fluoride on ZIWSC was studied as a function of contact time. It was noticed that the fluoride removal increased with the time. The adsorbent exhibited an initial gradual uptake of fluoride followed by a slower removal rate that gradually reached an equilibrium condition. Nearly $50 \%$ removal of fluoride was achieved, first $60 \mathrm{~min}$ of contact time and gradual increasing of removal occurred in the following $180 \mathrm{~min}$. Therefore 180 minutes was fixed as minimum contact time for the maximum defluoridation of the sorbent. The results compared with the other adsorbents to get good removal $[21,22,28]$.

3.2. Effect of Adsorbent Dose on the Adsorption Process. The effect of adsorbent dosage on the adsorption of fluoride for the initial concentration of $3.0 \mathrm{mg} / \mathrm{L}$ was studied. Adsorbent dosage varied from $0.5 \mathrm{gm}$ to $2.50 \mathrm{gm}$. It is seen that the 
adsorption increased with the increase in the dose of adsorbent. The maximum removal percentage was exhibited at a dosage of $1.5 \mathrm{gm}$ adsorbent per $100 \mathrm{~mL}$. Further addition of the adsorbent did not show a considerable increase in defluoridation, may be attributed to two reasons. The increase in sorbent dose at constant sorbent concentration and volume will lead to unsaturation of sorption sites through the sorption process $[29,30]$, and secondly may be due to particulate interaction such as aggregation resulting from high-sorbent dose [31].

3.3. Effect of $\mathrm{pH}$ on the Adsorption of Fluoride. The $\mathrm{pH}$ of the aqueous solution is an important variable, which controls the adsorption at the water-adsorbent interfaces. Therefore, the adsorption of fluoride on the ZIWSC was examined at different $\mathrm{pH}$ values ranging from 3 to 12 . It can be seen from the investigation that fluoride removal decreases with increasing $\mathrm{pH}$, and the removal of fluoride is maximum $94 \%$ (ZIWSC) and $81 \%$ (WSC) at $\mathrm{pH} 3$ and is minimum $22 \%$ (ZIWSC) and 18\% (WSC) at pH 12. This can be explained by the change of surface charge of the adsorbent. It is known that in highly acidic medium, the surface of adsorbent is highly protonated while it is neutralized and tended to have negative charge in alkaline medium. Therefore, high efficiency in acidic medium can be attributed to the gradual increase in attractive forces and low efficiency in alkaline medium can be explained by the repulsion between the negatively charged surface and fluoride. The $\mathrm{pH}_{\mathrm{zpc}}$ of WSC and ZIWSC are 5.2 and 4.6, respectively. However the percentage of fluoride removal by ZIWSC was higher than WSC in all the $\mathrm{pH}$ ranges studied.

3.4. Effect of Particle Size. The defluoridation experiments were conducted using WSC with five different particle sizes, namely <53, 53-106, 106-212, 212-300, and 300-426 microns. As the adsorption process is a surface phenomenon, the defluoridation efficiency is increased with decreasing of surface of the sample due to larger surface area. Therefore, with a given mass of walnut shell, smaller particle size would increase surface area availability hence the number of sites increased. Hence the material with particle size of $<53$ microns has been chosen for further experiments. All the forthcoming discussion is based on the experimental result using this sample.

3.5. Assessment of Influence of Interfering Co Ions. Defluoridation studies of ZIWSC were carried out in the presence of common ions like sulphate, chloride, bicarbonate, and nitrate, which are normally present in water, was experimentally verified. The concentration of coexisting ions was varied from $50 \mathrm{mg} / \mathrm{L}$ to $500 \mathrm{mg} / \mathrm{L}$ with an initial fluoride concentration of $10 \mathrm{mg} / \mathrm{L}$ at neutral $\mathrm{pH}$. It was inferred that there was no remarkable influence on the removal of fluoride in presence of $\mathrm{Cl}^{-}, \mathrm{SO}_{4}{ }^{2-}$, and nitrate. However, the presence of bicarbonate ion resulted in the decrease of percentage from $85.67 \%$ to $54.94 \%$. This may be due to the competition of bicarbonate ions with fluoride for sorption sites. Similar trend was reported while studying montmorrillonite as a sorbent for fluoride removal [32].

3.6. Adsorption Isotherms. The isotherm deals with relationship between the equilibrium amount of fluoride on the adsorbent and the solute concentration in solution. The fluoride sorption capacity of ZIWSC was evaluated using three different isotherms, namely Langmuir [33], Freundlich [34], and Temkin [35] isotherms.

The Langmuir isotherm model assumes that adsorption sites are energetically the same with monolayer formation and is generally expressed as

$$
\frac{C_{e}}{q_{e}}=\frac{1}{Q b}+\frac{C_{e}}{Q} .
$$

A plot of $C_{e} / q_{e}$ against $C_{e}$ should yield a straight line with $Q$ and $b$ obtained from the intercept and the slope. The value $Q$ is $3.53 \mathrm{mg} / \mathrm{g}$ and Langmuir constant $b$ is $3.11(\mathrm{~L} / \mathrm{mg})$. The results are summarized in Table 1 .

The essential characteristics of the Langmuir isotherms can be expressed in terms of dimensionless constant separation factor or equilibrium parameter, $R$, which is defined as [36]

$$
R=\frac{1}{\left(1+b C_{0}\right)},
$$

where $C_{0}$ is the initial fluoride concentration and $b$ is the Langmuir isotherm constant. The feasibility criteria of the process can be judged from $R$ values as follows:

$$
\begin{array}{ll}
\text { Value } & \text { Type } \\
R>1 & \text { unfavorable, } \\
R=0 & \text { irreversible, } \\
0<R<1 & \text { favorable, } \\
R=1 & \text { linear. }
\end{array}
$$

The $R$ values in Table 2 are also indicating favorable sorption of fluoride on to the adsorbent.

The Freundlich adsorption isotherm equation can be represented as follows:

$$
\ln q_{e}=\ln K_{f}+\left(\frac{1}{n}\right) \ln C_{e} .
$$

A plot of $\ln q_{e}$ against $\ln C_{e}$ should yield a straight line with slope $1 / n$ and intercept $\ln K_{f}$. It is found that the related correlation coefficient $r^{2}$ value for the Freundlich models is 0.982 .

Another equation used in the analysis of isotherm was the Temkin model is given as

$$
q_{e}=B_{1} \ln K_{T}+B_{1} \ln C_{e},
$$

where $B_{1}=R T / b$.

Temkin sorption contains a factor that explicity takes into the account adsorption species and adsorbent interaction. The heat of adsorption of all the molecules in the layer would 
decrease linearly with coverage due to adsorbate/adsorbate interaction [37]. This isotherm assumes that (i) the heat of adsorption of all the molecules in the layer decreases linearly with coverage due to adsorbent and adsorbate interactions, and that (ii) the adsorption is characterized by a uniform distribution of binding energy [38]. A plot of $q_{e}$ versus $\ln C_{e}$ enables the determination of the isotherm constants $B_{1}$ and $K_{T}$ from the slope and intercept, respectively. $K_{T}$ is the equilibrium binding constant $(\mathrm{L} / \mathrm{mol})$ corresponding to the maximum binding energy, and the constant $B_{1}$ is related to the heat of adsorption. A linear relationship between $q_{e}$ and $\ln$ $C_{e}$ indicates the applicability of this model to understand the adsorption mechanism. Temkin isotherm for the adsorption of fluoride and the corresponding constant are represented in Table 1. The higher $r^{2}$ values Freundlich of over Langmuir and Temkin isotherm indicated the suitability of Freundlich isotherm than the Langmuir and Temkin isotherm.

3.7. Thermodynamic Investigations. The effect of temperature has a major influence in the sorption process and hence the sorption of ZICNSC was monitored at four different temperatures $303,313,323$, and $333 \mathrm{~K}$ under the optimized condition and thermodynamic parameters, namely, standard free energy change $\left(\Delta \mathrm{G}^{\circ}\right)$, standard enthalpy change $\left(\Delta \mathrm{H}^{\circ}\right)$ and standard entropy change $\left(\Delta S^{\circ}\right)$ were calculated $[39,40]$ and presented in Table 3 . The negative values of $\Delta \mathrm{G}^{\circ}$ indicated the spontaneity of the sorption reaction. The positive values of $\Delta \mathrm{H}^{\circ}$ indicated the endothermic nature of the sorption process. The positive value of $\Delta S^{\circ}$ showed the increasing randomness at the solid/liquid interface during sorption of fluoride. Its also indicates the increased disorder in the system with changes in the hydration of adsorbing fluoride ions [41].

3.8. Adsorption Kinetics. The adsorption kinetics was studied with initial fluoride concentration 2, 4, 6, 8, and $10 \mathrm{mg} / \mathrm{L}$. The kinetics analysis of adsorption data is based on reaction kinetics of pseudo-first and pseudo-second-order mechanisms.The uptake of fluoride on zirconium impregnated adsorbent occurred rapidly, and reached equilibrium within $180 \mathrm{~min}$. The kinetics of adsorption was analyzed by using different rate equation. A pseudo-first-order rate expression or the Lagergren rate equation [42] is expressed as

$$
\ln \left(q_{e}-q_{t}\right)=\ln q_{e}-k_{1} t,
$$

where $q_{e}$ and $q_{t}$ are the fluoride on adsorbent $\left(\mathrm{mgg}^{-1}\right)$ at equilibrium and at time $t$, respectively, and $k_{1}\left(\mathrm{~min}^{-1}\right)$ is first-order rate constant. A plot of $\ln \left(q_{e}-q_{t}\right)$ against time $(t)$ should yield a straight line and the rate constant $k_{1}$ is evaluated from the slope.

The linear form of pseudo-second-order expression [43], is expressed as

$$
\frac{t}{q_{t}}=\left(\frac{1}{k_{2}}\right)\left(\frac{1}{q_{e}^{2}}\right)+\frac{t}{q_{e}} .
$$

$k_{2}$ can be determined by plotting $t / q_{t}$ against $t$ of (6) gives the straight line with higher correlation coefficient $r^{2}$ values, which is higher than that observed with pseudofirst-order model indicating the applicability of the pseudosecond-order model and the values are shown in Table 4 . From the model, the values of $q_{e}$ increased with increase in initial concentration and it also increased with increasing in Temperature. The values of rate constant $(k)$ have also increased with temperature indicating chemisorptions.

The adsorption process believed to follow a complex phenomenon is accompanied by both the surface and the pore diffusion, but to different extents. The extend of a particular diffusion to the total process may be estimated by a plot following the Weber and Morris equation [44] which is expressed as

$$
q_{t}=K_{d} \sqrt{t},
$$

where $K_{d}$, the date of pore diffusion, is obtained from the slope of the linear portion of the $q_{t}$ versus $\sqrt{t}$. The Weber and Morris plot reveals an initial curved portion (indicating of boundary layer effect, that is, surface adherence) followed by the linear portion yields (indicating of intraparticle or pore diffusion). The slope of the linear portion yields the $K_{d}$ value, while intercept of the plot signifies the extent of the boundary layer effect. The larger the intercept, the greater is the contribution of the surface adherence $[45,46]$ in the rate limiting steps. It is found that $K_{d}$ value increases with increased concentration and in lower temperature (Table 4).

3.9. Mechanism of Fluoride Sorption. The fluoride removal by ZIWSC was governed by adsorption mechanism. The surface acquired positive charge at lower $\mathrm{pH}$ values and hence the fluoride sorption at this $\mathrm{pH}$ level was mainly due to electrostatic attraction between the positive charged surface and negatively charged fluoride ions and chemisorption dominated. As the $\mathrm{pH}$ is increased slowly, the surface acquired negative charges, physisorption dominated and hence percentage removal of fluoride was decreased. The slight enhancement of fluoride removal by ZIWSC over WSC may be due to sorption by Zirconium, adsorption by physical forces and fluoride ion, a Lewis base, coordinates strongly with the Zirconium species adsorbed on WSC, which are Lewis acid sites:

$$
\mathrm{ZrO}(\mathrm{OH}) \mathrm{Cl} \text { (adsorbed on WSC) }+2 \mathrm{~F}^{-} \longleftrightarrow \mathrm{ZrOF}_{2} \text {. }
$$

The chemisorption mechanism of fluoride uptake, involves an exchange of the chloride and the hydroxide of the $\mathrm{ZrO}(\mathrm{OH}) \mathrm{Cl}$ species adsorbed on WSC by fluorides, leading to the formation of $\mathrm{ZrOF}_{2}$.

3.10. Desorption and Reuse Potential. Any adsorbent is economically viable if the adsorbent can be regenerated and reused in many cycles of operation. For checking the desorption capacity of the sorbent, the material was subjected to an adsorption at an initial fluoride concentration of $3 \mathrm{mg} / \mathrm{L}$. The exhausted ZIWSC was regenerated using $\mathrm{HCl}$ and $\mathrm{NaOH}$. $\mathrm{NaOH}$ is better regenerated than $\mathrm{HCl}$. The concentrations were ranging from $0 \%$ to $10 \%$. At $2.5 \% \mathrm{NaOH}$ concentration, ZIWSC had desorbed almost $96.2 \%$ of fluoride. To test 
TABLE 1: Linear isotherm parameters of fluoride adsorption on ZIWSC.

\begin{tabular}{lccccccrrr}
\hline \multirow{2}{*}{ Temp (K) } & \multicolumn{3}{c}{ Langmuir isotherm } & \multicolumn{3}{c}{ Freundlich parameters } & \multicolumn{3}{c}{ Redlich parameters } \\
& $Q(\mathrm{mg} / \mathrm{g})$ & $b(\mathrm{~L} / \mathrm{g})$ & $r^{2}$ & $K_{f}(\mathrm{mg} / \mathrm{g})$ & $1 / n$ & $r^{2}$ & $K_{T}(\mathrm{~L} / \mathrm{mol})$ & $B_{1}$ & $r^{2}$ \\
\hline 303 & 3.19 & 2.33 & 0.963 & 0.648 & 0.944 & 0.982 & 3.88 & 8.75 \\
313 & 3.01 & 2.62 & 0.954 & 0.590 & 0.932 & 0.983 & 7.12 & 4.20 \\
323 & 3.22 & 2.74 & 0.965 & 0.595 & 0.953 & 0.983 & 4.29 & 7.19 & 0.963 \\
333 & 3.53 & 3.11 & 0.919 & 0.643 & 0.944 & 0.980 & 7.76 & 6.85 & 0.964 \\
\hline
\end{tabular}

TABLE 2: $R_{L}$ values at different temperature.

\begin{tabular}{lccccc}
\hline S. No. & Conc. $\mathrm{F}^{-}(\mathrm{mg} / \mathrm{L})$ & $303 \mathrm{~K}$ & $313 \mathrm{~K}$ & $323 \mathrm{~K}$ & $333 \mathrm{~K}$ \\
\hline 1 & 2 & 0.1766 & 0.1602 & 0.1543 & 0.1382 \\
2 & 4 & 0.0969 & 0.0871 & 0.0836 & 0.0742 \\
3 & 6 & 0.0667 & 0.0598 & 0.0573 & 0.0507 \\
4 & 8 & 0.0509 & 0.0455 & 0.0436 & 0.0385 \\
5 & 10 & 0.0411 & 0.0367 & 0.0352 & 0.0311 \\
\hline
\end{tabular}

TAble 3: Thermodynamic Parameters for Adsorption of fluoride onto ZIWSC.

\begin{tabular}{lccc}
\hline S. No. & $\begin{array}{c}\text { Thermodynamic } \\
\text { parameters }\end{array}$ & Temperature $(\mathrm{K})$ & Values \\
\hline & & 303 & -0.9282 \\
1 & $\Delta G\left(\mathrm{~kJ} \mathrm{~mol}^{-1}\right)$ & 313 & -1.0545 \\
& & 323 & -1.1043 \\
& & 333 & -1.2394 \\
3 & $\Delta H\left(\mathrm{~kJ} \mathrm{~mol}^{-1}\right)$ & & 3.3157 \\
3 & $\Delta S\left(\mathrm{~J} \mathrm{~mol}^{-1} \mathrm{~K}^{-1}\right)$ & & 14.0131 \\
\hline
\end{tabular}

the adsorption potential of regenerated ZIWSC, two more cycles of adsorption-desorption studies were carried out by maintaining the initial conditions the same. In third cycle, the adsorbent capacity has shown $28.00 \%$. However, in the fourth cycle, adsorption capacity was observed as 5\%. More tests have to be conducted to determine the exact life cycle of the adsorbent.

3.11. Field Study. In order to gain the practical utility of the studied carbonaceous adsorbents, batch studies were preformed to evaluate their viability for real field application. The samples from fluorosis affected areas of Tirunelveli district, India having higher concentrations of fluoride were collected and adsorption studies were performed (adsorbent: $1.5 \mathrm{~g}$; temperature: $303 \mathrm{~K}$; agitation: $200 \mathrm{rpm}$; $\mathrm{pH}$ : 7). The consolidated experimental results for all the water samples studied with the function of adsorbents are depicted in Table 5. The sorption data phenomena were found to be dependent on the concentration of fluoride in the water sample used. It has been observed that all the water quality parameters show marked improvement.

3.12. Instrumental Studies. For understanding the nature of fluoride sorption X-ray and FTIR studies were performed

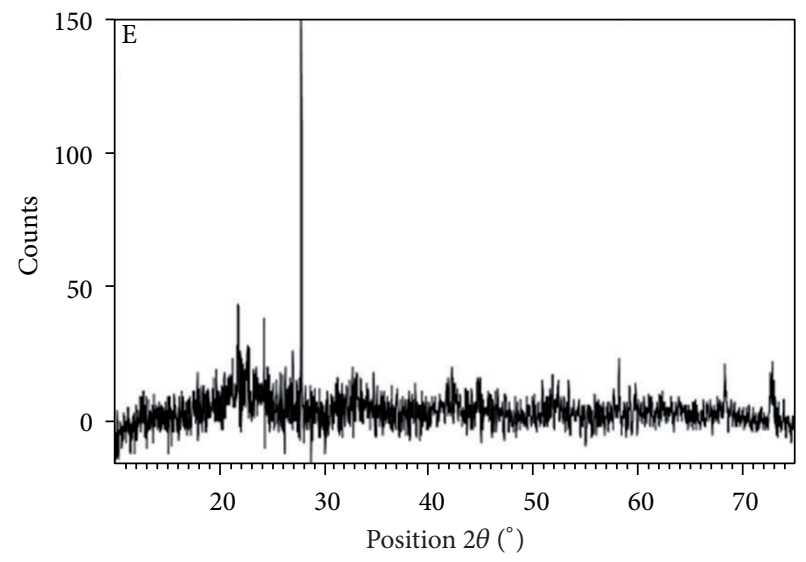

FIGURE 1: X-ray diffraction pattern of ZIWSC.

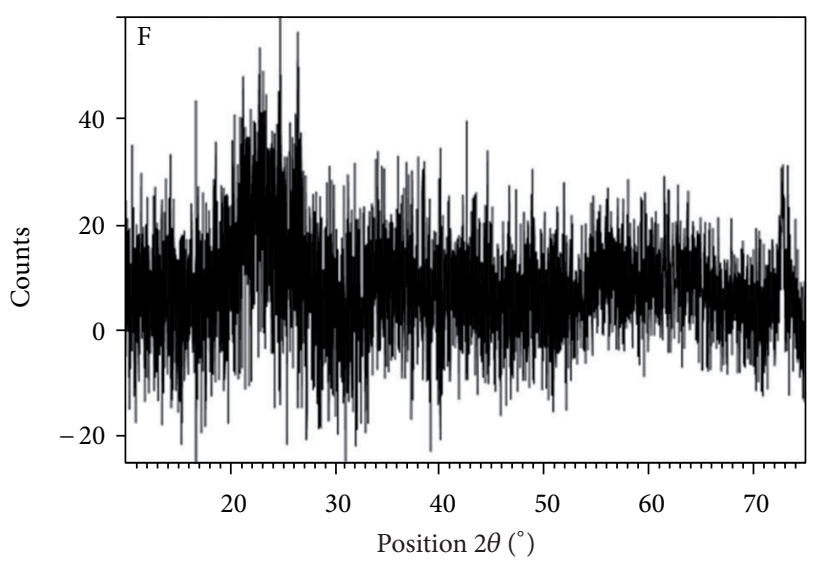

FIGURE 2: X-ray diffraction pattern of fluoride adsorbed on ZIWSC.

using the raw and treated adsorbents. Powder X-ray diffraction was carried out on the raw and fluoride treated ZIWSC samples. The XRD patterns for treated adsorbents showed significant changes. The XRD data of the treated ZIWSC provided evidence of slight modification over the crystal cleavages. The intensity of the peak due to the hkl plane 010 of the monoclinic crystal system of ZIWSC disappeared after the fluoride adsorption on its surface. This is possible due to the lattice dislocation in the crystal system. The X-ray diffraction patterns of raw and fluoride treated material are given in Figures 1 and 2.

The surface condition and the existence of fluoride onto ZIWSC were confirmed by the SEM with EDAX analysis. 
TABLE 4: Kinetic parameters of values of ZIWSC.

\begin{tabular}{lccccccc}
\hline $\mathrm{F}^{-}(\mathrm{mg} / \mathrm{L})$ & \multicolumn{3}{c}{ Pseudo-First order } & \multicolumn{3}{c}{ Pseudo-Second order } & \multicolumn{2}{c}{ Intraparticle diffusion } \\
& $K_{1}\left(\mathrm{~min}^{-1}\right)$ & $q_{e}(\mathrm{mg} / \mathrm{g})$ & $r^{2}$ & $K_{2}(\mathrm{~g} / \mathrm{mg} \mathrm{min})$ & $q_{e}(\mathrm{mg} / \mathrm{g})$ & $r^{2}$ & $K_{d}\left(\mathrm{~min}^{-1}\right)$ \\
\hline 2 & 0.0154 & 0.905 & 0.991 & 0.0188 & 1.34 & 0.998 & 0.79 \\
4 & 0.0138 & 1.159 & 0.959 & 0.0094 & 2.72 & 0.996 & 1.60 \\
6 & 0.0161 & 1.481 & 0.983 & 0.0066 & 4.15 & 0.998 & 2.47 \\
8 & 0.0145 & 1.421 & 0.994 & 0.0073 & 5.32 & 0.999 & 3.30 \\
10 & 0.0156 & 1.366 & 0.952 & 0.0104 & 6.38 & 0.999 & 4.11 \\
\hline
\end{tabular}

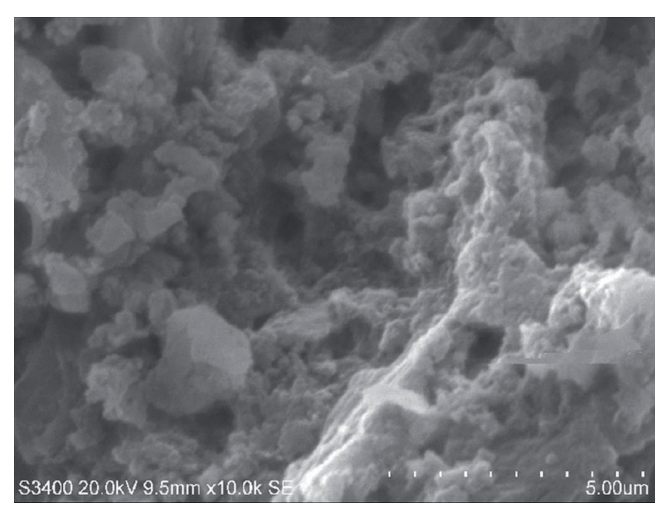

(a)

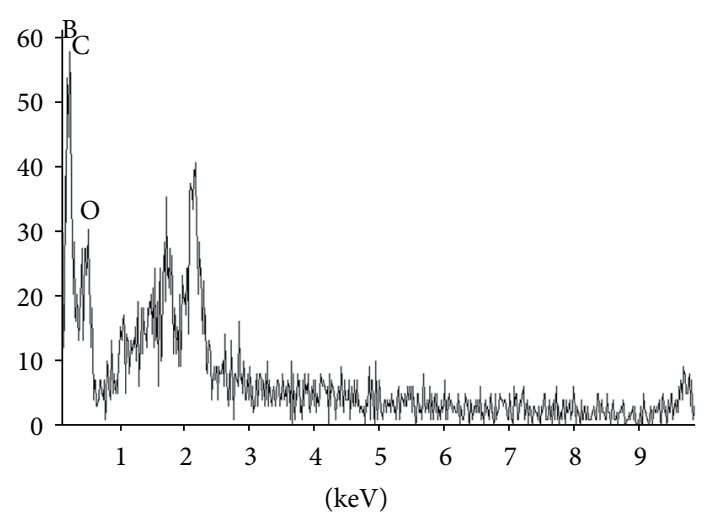

(c)

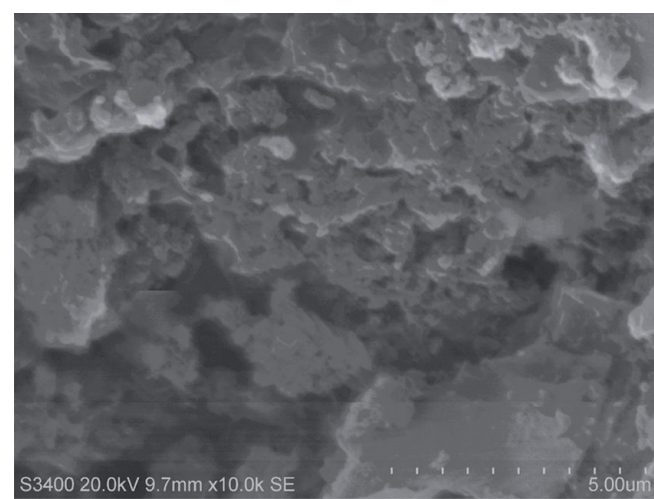

(b)

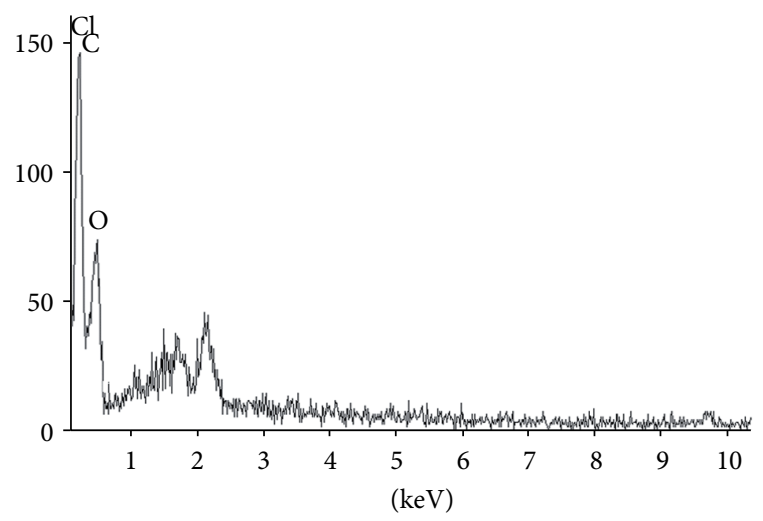

(d)

FIGURE 3: SEM images of (a) ZIWSC and (b) fluoride-sorbed ZIWSC, and EDAX spectra of (c) ZIWSC and (d) fluoride-sorbed ZIWSC.

TABLE 5: Field trial results of ZIWSC.

\begin{tabular}{lcc}
\hline $\begin{array}{l}\text { Water quality } \\
\text { parameters }\end{array}$ & Before treatment & After treatment \\
\hline $\mathrm{F}^{-}(\mathrm{mg} / \mathrm{L})$ & 3.6 & 0.53 \\
$\mathrm{pH}$ & 8.1 & 7.1 \\
$\mathrm{EC}\left(\mathrm{mmho} / \mathrm{cm}^{2}\right)$ & 4.16 & 1.44 \\
$\mathrm{Cl}^{-}(\mathrm{mg} / \mathrm{L})$ & 463 & 222 \\
$\mathrm{TH}(\mathrm{mg} / \mathrm{L})$ & 496 & 201 \\
$\mathrm{TA}(\mathrm{mg} / \mathrm{L})$ & 467 & 212 \\
\hline
\end{tabular}

Figures 3(a) and 3(b) show the SEM images before and after fluoride sorption with ZIWSC. The changes in the surface morphology of adsorption before and after fluoride treatment indicate fluoride sorption on ZIWSC. The EDAX spectrum of ZIWSC confirms the elements present in it and is shown in Figure 3(c). The presence of a fluoride peak in the EDAX spectra of fluoride-sorbed ZIWSC confirms the fluoride sorption onto ZIWSC, which is shown in Figure 3(d).

\section{Conclusions}

The impregnated walnut shell acts as a reasonably good adsorbent for the removal of fluoride from aqueous solution. The optimum $\mathrm{pH}$ for removal was found to be 3.0, at which fluoride removal was $94 \%$. The removal increased with the increase in the adsorbate concentration. An increasing equilibrium adsorption capacity with the rise in temperature indicated that the nature of adsorption process is endothermic, which is further supported by the thermodynamic parameters calculated from the Langmuir isotherm at various 
temperatures. The adsorption process was found to follow the Freundlich adsorption isotherm model and Pseudo-secondorder. Compared to the various other sorbents reported in the literature, the impregnated walnut shell in this study shows very good promise for practical applicability. However, more studies are needed to optimize the system from the regeneration point of view and to investigate the economic aspects.

\section{Acknowledgment}

The financial support for the project by the University Grants Commission (UGC), Government of India, New Delhi under the Major Research Project F. no. 32-296/2006 (SR) is gratefully acknowledged.

\section{References}

[1] C. Reimann, K. Bjorvatn, B. Frengstad, Z. Melaku, R. TekleHaimanot, and U. Siewers, "Drinking water quality in the Ethiopian section of the East African Rift Valley I-data and health aspects," Science of the Total Environment, vol. 311, no. 1-3, pp. 65-80, 2003.

[2] "[PHE] Protection of the Human Environment, Fluoride in drinking water," 2001.

[3] K. Kim and G. Y. Jeong, "Factors influencing natural occurrence of fluoride-rich groundwaters: a case study in the southeastern part of the Korean Peninsula," Chemosphere, vol. 58, no. 10, pp. 1399-1408, 2005.

[4] S. Das, B. C. Mehta, S. K. Samanta, P. K. Das, and S. K. Srivastava, "Fluoride hazards in ground water of Orissa, India," Indian Journal of Environmental Health, vol. 42, no. 1, pp. 40-46, 2000.

[5] S. Ayoob and A. K. Gupta, "Fluoride in drinking water: a review on the status and strees effects," Critical Reviews in Environmental Science and Technology, vol. 36, pp. 433-487, 2006.

[6] A. K. Susheela, A. Kumar, M. Bhatnagar, and R. Bahadur, "Prevalence of endemic fluorosis with gastrointestinal manifestations in people living in some North-Indian villages," Fluoride, vol. 26, no. 2, pp. 97-104, 1993.

[7] S. Saha, "Treatment of aqueous effluent for fluoride," Water Research, vol. 27, no. 8, pp. 1347-1350, 1993.

[8] N. Parthasarathy, J. Buffle, and W. Haerdi, "Combined use of calcium salts and polymeric aluminium hydroxide for defluoridation of waste waters," Water Research, vol. 20, no. 4, pp. 443-448, 1986.

[9] H. Mjengera and G. Mkongo, "Appropriate deflouridation technology for use in flourotic areas in Tanzania," Physics and Chemistry of the Earth, vol. 28, no. 20-27, pp. 1097-1104, 2003.

[10] S. Zafar Qureshi, M. Ahmad Khan, and N. Rahman, "Removal of fluoride ion by zirconium (VI) arsenate vanadate using ionselective electrode," Water Treatment, vol. 10, no. 4, pp. 307-312, 1995.

[11] R. L. Dorst, in Theory and Practice of Water and Waste Treatment, pp. 457-512, Wiley, New York, NY, USA, 1997.

[12] S. S. Tripathy, J. L. Bersillon, and K. Gopal, "Removal of fluoride from drinking water by adsorption onto alum-impregnated activated alumina," Separation and Purification Technology, vol. 50, no. 3, pp. 310-317, 2006.
[13] D. Mohapatra, D. Mishra, S. P. Mishra, G. Roy Chaudhury, and R. P. Das, "Use of oxide minerals to abate fluoride from water," Journal of Colloid and Interface Science, vol. 275, no. 2, pp. 355-359, 2004.

[14] M. Sarkar, A. Banerjee, P. P. Pramanick, and A. R. Sarkar, "Use of laterite for the removal of fluoride from contaminated drinking water," Journal of Colloid and Interface Science, vol. 302, no. 2, pp. 432-441, 2006.

[15] A. Tor, "Removal of fluoride from an aqueous solution by using montmorillonite," Desalination, vol. 201, no. 1-3, pp. 267-276, 2006.

[16] P. P. Coetzee, L. L. Coetzee, R. Puka, and S. Mubenga, "Characterisation of selected South African clays for defluoridation of natural waters," Water SA, vol. 29, no. 3, pp. 331-338, 2003.

[17] X. Fan, D. J. Parker, and M. D. Smith, "Adsorption kinetics of fluoride on low cost materials," Water Research, vol. 37, no. 20, pp. 4929-4937, 2003.

[18] R. L. Ramos, J. Ovalle-Turrubiartes, and M. A. Sanchez-Castillo, "Adsorption of fluoride from aqueous solution on aluminumimpregnated carbon," Carbon, vol. 37, no. 4, pp. 609-617, 1999.

[19] M. S. Onyango, Y. Kojima, O. Aoyi, E. C. Bernardo, and H. Matsuda, "Adsorption equilibrium modeling and solution chemistry dependence of fluoride removal from water by trivalent-cation-exchanged zeolite F-9," Journal of Colloid and Interface Science, vol. 279, no. 2, pp. 341-350, 2004.

[20] S. Chidambaram, A. L. Ramanathan, and S. Vasudevan, "Fluoride removal studies in water using natural materials," Water SA, vol. 29, no. 3, pp. 339-343, 2003.

[21] G. Alagumuthu and M. Rajan, "Equilibrium and kinetics of adsorption of fluoride onto zirconium impregnated cashew nut shell carbon," Chemical Engineering Journal, vol. 158, no. 3, pp. 451-457, 2010.

[22] G. Alagumuthu and M. Rajan, "Kinetic and equilibrium studies on fluoride removal by zirconium (iv)-impregnated groundnut shell carbon," Hemijska Industrija, vol. 64, no. 4, pp. 295-304, 2010.

[23] M. M. Johns, W. E. Marshall, and C. A. Toles, "Agricultural by products as granular activated carbons for adsorping dissolved metals and organics," Journal of Chemical Technology and Biotechnology, vol. 71, pp. 131-140, 1998.

[24] D. Seethapathirao, "Defluoridation water using sulphated coconut shell carbon," Indian Journal of Environmental Health, vol. 64, pp. 11-12, 1964.

[25] J. H. Kennedy, Analytical Chemistry Principles, W.B. Saunder, New York, NY, USA, 2nd edition, 1990.

[26] [APHA] American Public Health Association, Washington, DC, 2005.

[27] M. V. Lopez-Ramon, F. Stoeckli, C. Moreno-Castilla, and F. Carrasco-Marin, "On the characterization of acidic and basic surface sites on carbons by various techniques," Carbon, vol. 37, no. 8, pp. 1215-1221, 1999.

[28] V. Veeraputhiran and G. Alagumuthu, "Treatment of high fluoride drinking water using bioadsorbent," Research Journal of Chemical Sciences, vol. 1, pp. 49-54, 2011.

[29] A. Shukla, Y. H. Zhang, P. Dubey, J. L. Margrave, and S. S. Shukla, "The role of sawdust in the removal of unwanted materials from water," Journal of Hazardous Materials, vol. 95, no. 1-2, pp. 137-152, 2002.

[30] L. J. Yu, S. S. Shukla, K. L. Dorris, A. Shukla, and J. L. Margrave, "Adsorption of chromium from aqueous solutions by maple sawdust," Journal of Hazardous Materials, vol. 100, no. 1-3, pp. 53-63, 2003. 
[31] M. Özacar and I. A. Şengil, "Adsorption of metal complex dyes from aqueous solutions by pine sawdust," Bioresource Technology, vol. 96, no. 7, pp. 791-795, 2005.

[32] G. Karthikeyan, A. Pius, and G. Alagumuthu, "Fluoride adsorption studies of montmorillonite clay," Indian Journal of Chemical Technology, vol. 12, no. 3, pp. 263-272, 2005.

[33] I. Langmuir, "The constitution and fundamental properties of solids and liquids. Part I. Solids," The Journal of the American Chemical Society, vol. 38, no. 2, pp. 2221-2295, 1916.

[34] H. M. F. Freundlich, "Uber die adsorption in losungen," Zeitschrift für Physikalische Chemie A, vol. 57, pp. 385-470, 1906.

[35] W. Nigussie, F. Zewge, and B. S. Chandravanshi, "Removal of excess fluoride from water using waste residue from alum manufacturing process," Journal of Hazardous Materials, vol. 147, no. 3, pp. 954-963, 2007.

[36] M. Prasad, S. Saxena, S. S. Amritphale, and N. Chandra, "Kinetics and isotherms for aqueous lead adsorption by natural minerals," Industrial and Engineering Chemistry Research, vol. 39, no. 8, pp. 3034-3037, 2000.

[37] M. Hosseini, S. F. L. Mertens, M. Ghorbani, and M. R. Arshadi, "Asymmetrical Schiff bases as inhibitors of mild steel corrosion in sulphuric acid media," Materials Chemistry and Physics, vol. 78, no. 3, pp. 800-808, 2003.

[38] Y. Kim, C. Kim, I. Choi, S. Rengaraj, and J. Yi, "Arsenic removal using mesoporous alumina prepared via a templating method," Environmental Science and Technology, vol. 38, no. 3, pp. 924-931, 2004.

[39] A. A. Khan and R. P. Singh, "Adsorption thermodynamics of carbofuran on Sn (IV) arsenosilicate in $\mathrm{H}^{+}, \mathrm{Na}^{+}$and $\mathrm{Ca}^{2+}$ forms," Colloids and Surfaces, vol. 24, no. 1, pp. 33-42, 1987.

[40] M. Horsfall and A. I. Spiff, "Effects of temperature on the sorption of $\mathrm{Pb} 2+$ and $\mathrm{Cd} 2+$ from aqueous solution by Caladium bicolor (Wild Cocoyam) biomass," Electronic Journal of Biotechnology, vol. 8, no. 2, pp. 162-169, 2005.

[41] E. Eren, "Removal of copper ions by modified Unye clay, Turkey," Journal of Hazardous Materials, vol. 159, no. 2-3, pp. 235-244, 2008.

[42] K. Periasamy and C. Namasivam, "Process development for the removal and recovery of calcium from wastewater by a Low cost adsorbent," Industrial \& Engineering Chemistry Research, vol. 33, pp. 317-320, 1994.

[43] Y. S. Ho, "Second-order kinetic model for the sorption of cadmium onto tree fern: a comparison of linear and non-linear methods," Water Research, vol. 40, no. 1, pp. 119-125, 2006.

[44] W. J. Weber and J. C. Morris, "Kinetics of adsorption of carbon from solution," Journal of the Sanitary Engineering Division, vol. 33, p. 317, 1963.

[45] A. K. Chaturvedi, K. C. Pathak, and V. N. Singh, "Fluoride removal from water by adsorption on China clay," Applied Clay Science, vol. 3, no. 4, pp. 337-346, 1988.

[46] S. H. Lo and O. J. Sproul, "Polio virus adsorption from water onto silicate minerals," Water Research, vol. 11, no. 8, pp. 653-658, 1977. 

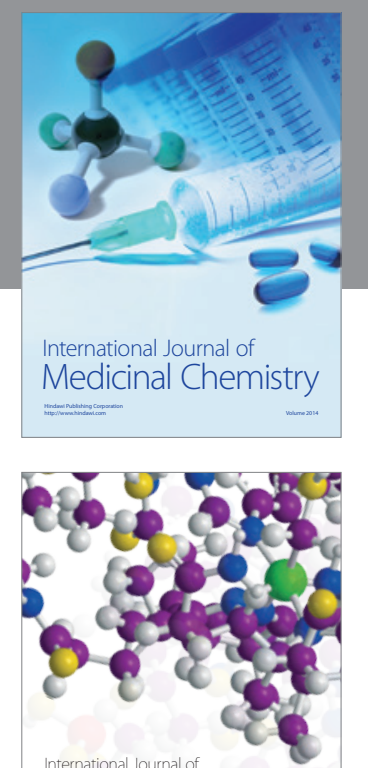

\section{Carbohydrate} Chemistry

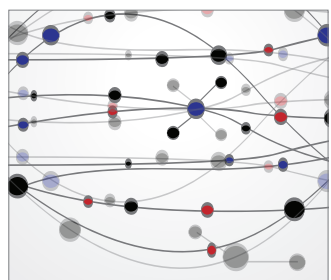

The Scientific World Journal
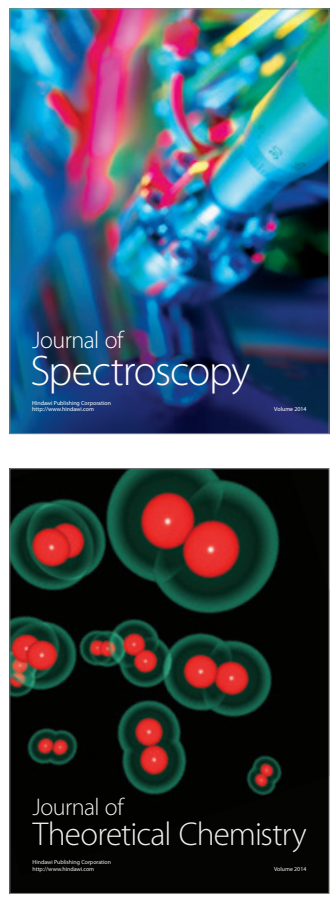
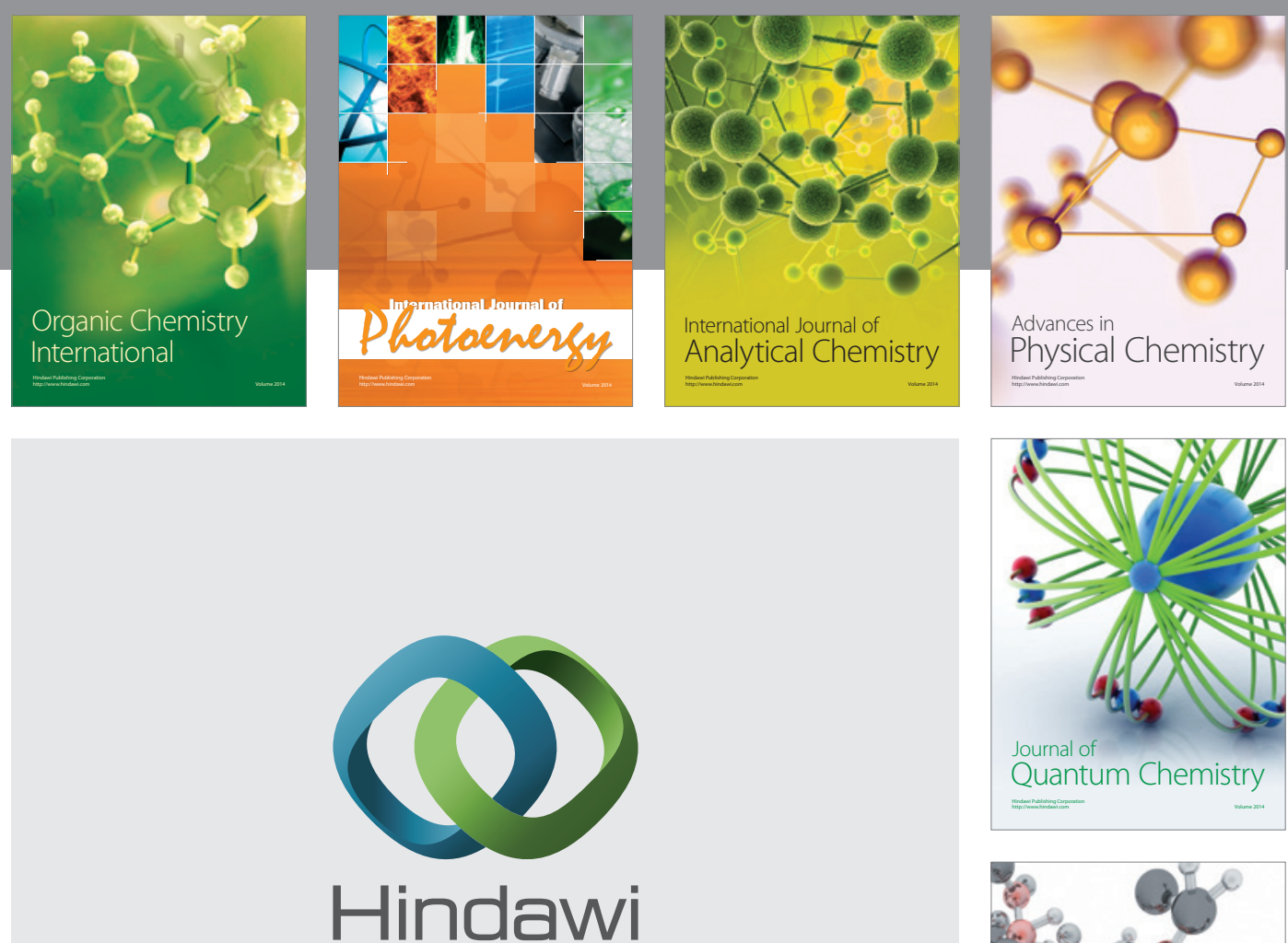

Submit your manuscripts at

http://www.hindawi.com

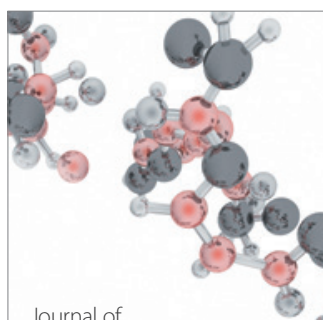

Analytical Methods

in Chemistry

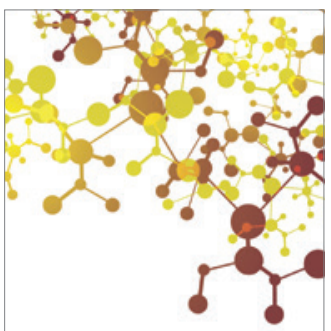

Journal of

Applied Chemistry

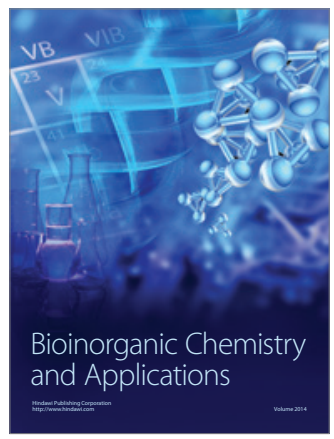

Inorganic Chemistry
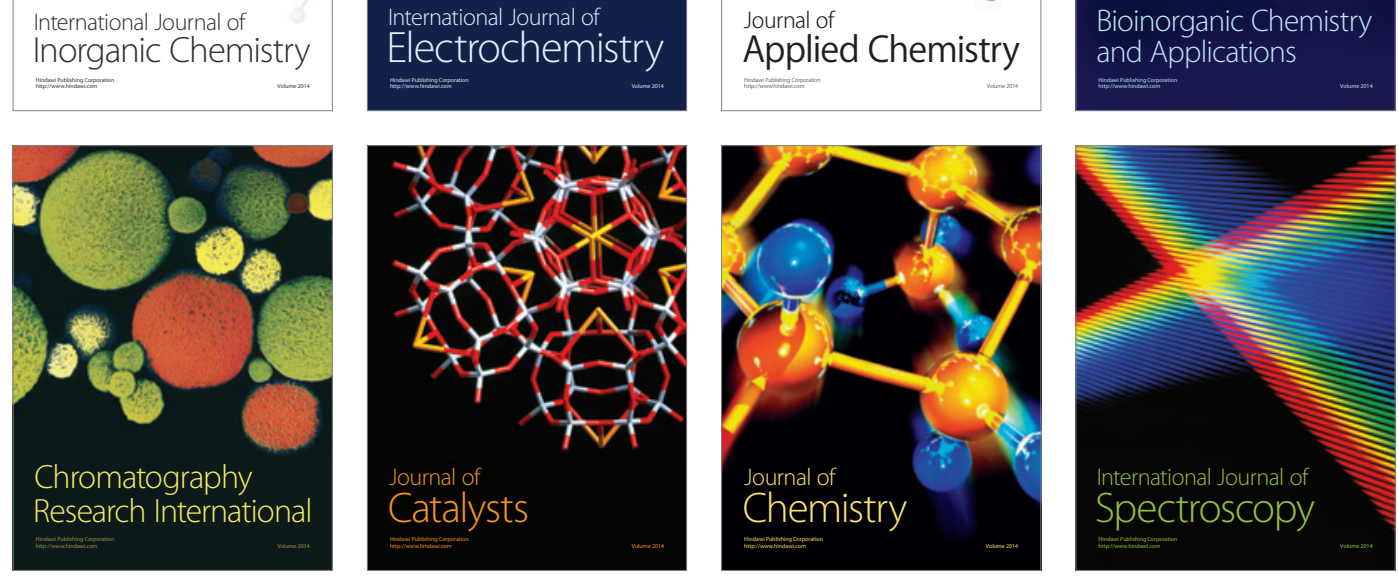